\title{
Ancestors and the sun: astronomy, architecture and culture at Chaco Canyon
}

\author{
Andrew M. Munro ${ }^{1}$ and J. McKim Malville ${ }^{2}$ \\ ${ }^{1}$ Centre for Astronomy, James Cook University, Townsville, Queensland 4811, Australia \\ email: andrew.munro@my.jcu.edu.au \\ ${ }^{2}$ Department of Astrophysical and Planetary Sciences, University of Colorado, \\ Boulder CO, 80309, USA and \\ Centre for Astronomy, James Cook University, Townsville, Queensland 4811, Australia \\ email: kimmalville@hotmail.com
}

\begin{abstract}
Three architectural traditions with astronomical associations have been identified among the 'Great Houses' and 'Great Kivas' of Chaco Canyon, New Mexico. Great Houses and one Great Kiva built during the height of construction activity (AD 1020-1100), the Bonito Phase, include front-facing south-southeast (SSE) orientations, and cardinal north-south and/or east-west (NS/EW) alignments. We present ethnographic material supporting our previous proposal that the SSE orientation is probably linked to migration traditions and ancestor veneration. We also confirm that a majority of Late Bonito Phase Great Houses (built after A.D. 1100) exhibit a third astronomical tradition: five of the principal in-canyon Great Houses built at that time were positioned at or near observing locations that could have functioned as solstice calendrical stations. Through use of these locations for public ceremonies, the Chacoan elite could demonstrate astronomical knowledge and ritual power. These findings provide support for Van Dyke's hypothesis that construction during this period was intended to reinvigorate a faltering system. One 'Chaco halo' Great House, Bis sa'ani, incorporates all three traditions. We suggest that temporal analysis of these traditions improves understanding of migration paths and shifting balances of power and social dominance among ancestral Pueblo culture groups.
\end{abstract}

Keywords. Chaco Canyon, Great House, cardinal NS/EW alignment, SSE orientation, solstice calendrical station

\section{Introduction: the Chaco phenomenon}

During the 11th and 12th centuries AD, ancestral Pueblo people built monumental architecture and a complex regional system in what is now the Southwestern United States. Twelve monumental 'Great Houses' survive at Chaco Canyon, the largest of which stood 4 or 5 stories high and covered an area exceeding 18,000 $\mathrm{m}^{2}$. Early structures at Chaco $(\sim$ AD 860-900) were not characteristically greater in stature than the architecture in surrounding communities, i.e. Prudden Unit type houses, but by the 11th century the resources dedicated to the construction of monumental architecture achieved a remarkable scale. Hundreds of thousands of timbers harvested from the Chuska Mountains and elsewhere were hauled over distances of $75-100 \mathrm{~km}$ to the canyon by hand. These were incorporated into massive core and veneer masonry Great Houses built with local sandstone (see e.g., Lister \& Lister 1981; Lekson 1984, 2006; Noble 2004; Van Dyke 2008).

The $13 \mathrm{~km}$ stretch of Chaco Canyon containing the twelve most famous ruins lies at the core of a regional system that spanned thousands of $\mathrm{km}^{2}$. Over 150 Great Houses have been identified. 'Chaco Outlier' Great Houses are characterized by the presence of one or more of: an imposing 'Great House' that is architecturally dissimilar from surrounding habitations, ceremonial round rooms called 'Great Kivas' exceeding 100 m² $^{2}$ 
in area, formalized roads or road segments, and/or earthworks. Archaeologists debate which communities to include in the Chacoan regional system, and how to interpret the structure of that system. Much of the debate centers on the 'Chacoan characteristics' found at each site, and the degree to which identified material evidence conforms to 'Chacoan' norms (see. e.g., Kantner \& Mahoney 2000; Kantner \& Kintigh 2006; Kincaid 1983; Powers et al. 1983; Van Dyke 2008; Wilcox 2004).

Pueblo culture is diverse; four distinct language families exist among the twenty modern Pueblos in New Mexico and Arizona. Among these people, varied ancestral migration traditions and spiritual practices operate within Pueblos, clans, religious societies, and moieties. Given that over nine centuries passed between the 'Chaco Fluorescence' and initial 19th-century anthropological documentation of Pueblo culture, ethnographic data must be applied cautiously. Nonetheless, there are widely-shared cosmological and astronomical concepts among Pueblo people that are consistent with Chacoan material evidence. The cardinal directions (NS/EW) or inter-cardinals are important in cosmogony and ritual systems. Also of importance are the concepts of 'Center Place', dualism and symmetry. In addition, while traditional Pueblo ritual and agricultural calendars vary, they commonly integrate solar horizon calendars and moon phase observations to identify dates of importance. Sky watching has remained socially and ritually important in the post-contact period (see e.g., McCluskey 1977; Ortiz 1969: 14-15, 20-23; Stirling 1942: 5-6, 8-11, 19, 24; Snead \& Preucel 1999; Zeilik 1985a, 1985b, 1986, 1989).

\section{Astronomy and architecture}

This paper reevaluates the orientation or location of 24 Chacoan Great Houses and one Great Kiva. Using new field studies and analyses of previously published site plans we find that a majority of these structures conform to one or more of three astronomicallylinked traditions. Most are either: 1) oriented (front-facing) to the SSE, usually between $151^{\circ}$ and $\left.161^{\circ} ; 2\right)$ individually aligned and/or aligned inter-site to the cardinal directions (NS/EW); and/or 3) built at workable horizon calendrical stations incorporating a dramatic solstice sunrise or sunset. Table 1 presents the structures considered, their front-facing azimuths, inter-site cardinal alignments created by their construction, and solstice horizon calendar foresights observable from each (where 'JSR' = June Solstice Rise, 'JSS' = June Solstice Set, and 'DSR' = December Solstice Rise). These Great Houses and Kivas are grouped into two regional associations: the first 22 entries are all within Chaco Canyon or the surrounding region, the final five are located to the north of Chaco in the Totah region. Within the table, orientations listed to $0.1^{\circ}$ are based upon fieldwork conducted between 2007 and 2010. Orientations listed as approximate (' $\sim$ ') are taken from published site drawings. Pueblo Bonito is listed twice, once for its original 'C'-shaped room block ca. AD 860-925, and a second time for its final expansion and reorientation to cardinal NS/EW after AD 1075. The lack of 'front facing azimuth' data for five Great Houses is due to the fact that interpreting a 'facing' azimuth for these structures is problematic owing to their designs. The orientations listed for the three Great Houses at Aztec include two that face SSE and one (Aztec North) that is cardinal. However, because Aztec North has never been excavated, the NS $\left(\sim 180^{\circ}\right)$ interpretation for this structure is not well constrained.

\subsection{SSE orientation}

Hayes (1981: 59-61) first noted the dominance of the multi-century front-facing SSE orientation tradition for ancestral Pueblo architecture. This tradition predates Great House construction, and is identifiable among Basketmaker III phase pit structures (AD 400-700), as well as early to mid Pueblo I (AD 700-850) 'Prudden Units' across a wide area. 
Table 1. Orientations, alignments and solstice associations among studied Great Houses and Kivas.

\begin{tabular}{|c|c|c|c|c|c|}
\hline Structure & $\begin{array}{l}\text { Construction } \\
\text { start (AD) }\end{array}$ & Date source & Front-facing AZ & $\begin{array}{l}\text { Inter-site } \\
\text { alignment }\end{array}$ & $\begin{array}{l}\text { Calen- } \\
\text { drical } \\
\text { station }\end{array}$ \\
\hline Pueblo Bonito I ('PB') & $860-925$ & Stein et al. 2003 & $\sim 161^{\circ}$ & - & JSR \\
\hline Peñasco Blanco & 900 & Lekson 1984: 104 & $\sim 113^{\circ}-116^{\circ}$ & - & - \\
\hline Una Vida & $860-865$ & Lekson 1984: 88 & $\sim 151^{\circ}$ & - & - \\
\hline Kin Nahasbas & $900 \mathrm{~s}$ & Mathien \& Windes 1988 & $\sim 205^{\circ}$ & - & - \\
\hline Kin Bineola & $860-900$ & Sebastian \& Altschul 1986 & $170.1^{\circ}$ & - & - \\
\hline East Community & 900 & Windes et al. 2000 & $\sim 159^{\circ}$ & - & - \\
\hline Pueblo Pintado & 900 & Windes \& Ford 1992 & $160.3^{\circ}$ & - & - \\
\hline Hungo Pavi & $990-1010$ & Lekson 1984: 152 & $184.8^{\circ}$ & - & - \\
\hline Chetro Ketl & $1010-1030$ & Lekson 1984: 173 & $160.2^{\circ}$ & $\mathrm{EW}$ to $\mathrm{PB}$ & - \\
\hline Pueblo Alto ('PA') & 1040 & Windes 1984 & $178.9^{\circ}$ & - & - \\
\hline Pueblo del Arroyo & $1065-1070$ & Lekson 1984: 210 & $114.9^{\circ}$ & - & - \\
\hline Casa Rinconada ('CR') & $1060-1110$ & Vivian \& Reiter 1960 & $180.1^{\circ}$ & - & - \\
\hline $\begin{array}{l}\text { Pueblo Bonito (reorien- } \\
\text { ted) }\end{array}$ & $1075+$ & Stein et al. 2003 & $180.2^{\circ}$ & - & JSR \\
\hline Tsin Kletsin & $1110-1115$ & Lekson 1984: 231 & $178.7^{\circ}$ & NS to PA & - \\
\hline New Alto & $1100-1130$ & Lekson 1984: 251 & - & $\begin{array}{l}\text { NS to } \mathrm{CR} \\
\mathrm{EW} \text { to } \mathrm{PA}\end{array}$ & - \\
\hline Wijiji & $1110-1115$ & Lekson 1984: 224 & $\sim 172^{\circ}$ & - & DSR \\
\hline Kin Kletso & $1125-1130$ & Lekson 1984: 238 & - & - & DSR \\
\hline Casa Chiquita & $1100-1130$ & Lekson 1984: 246 & - & - & JSS \\
\hline Headquarters Site A & $1100-1130$ & Lister \& Lister 1981: 252 & - & - & DSR \\
\hline Roberts Small Pueblo & $1100 \mathrm{~s}$ & Lister \& Lister 1981: 240 & - & - & - \\
\hline Bis sa'ani & early $1100 \mathrm{~s}$ & Powers et al. 1983: 21 & $178.9^{\circ} \& \sim 154^{\circ}$ & - & JSR \\
\hline Salmon & $1066-1072$ & Baker 2008 & $\sim 155.8^{\circ}$ & - & - \\
\hline Chimney Rock & 1076 & Eddy 1977 & $\sim 156^{\circ}$ & - & JSR \\
\hline Aztec North & $1110-1120$ & Brown et al. 2008 & $\sim 180^{\circ}$ & - & - \\
\hline Aztec East \& West (2) & $1110-1120$ & Brown et al. 2008 & $\sim 153^{\circ}-\sim 160^{\circ}$ & - & - \\
\hline
\end{tabular}

The front-facing orientations of Chacoan Great Houses are consistent with the orientations of the primary axes of much earlier pit structures in the (AD 450-700) villages of Shabik'eschee and 29SJ 423 at Chaco (Malville \& Munro 2009). The identification of the 'front facing' design of these pithouses is based on their well-defined axes of bilateral symmetry through internal features including sipapus, hearths, deflector stones, and entrances. We found that a majority of the structures in the two villages were front facing to between $151^{\circ}$ and $161^{\circ}$.

Later northern San Juan and southern Colorado villages containing Prudden Unit houses (AD 700-850) were being abandoned at about the same time as Great House construction began at Chaco (Lekson et al. 2006; Lipe 2006; Wilshusen \& Van Dyke 2006). Architectural and material culture evidence led Cameron (2009: 20) to suggest that immigrants from these villages established the Chacoan 'identity'. The early Great Houses in Chaco appear to be "monumentally scaled-up versions of unit pueblos" (Lekson 2009: 123). Reed (1956) discussed front-facing Prudden Unit pueblos, each with a room block overlooking a kiva containing a well-defined axis of bilateral symmetry. We have assessed multiple villages from this period using the records of the Dolores Project, and again found consistent SSE orientations.

Among SSE-facing Chacoan Great Houses constructed after AD 900, there has been an unfortunate emphasis in the literature on back-wall alignments, perpendicular to the buildings' axes of symmetry. This emphasis has yielded claims of June solstice and minor lunar standstill alignments for a subset of the Great Houses (Lekson 2009; Sofaer 2007). We disagree with these claims on multiple grounds. We find no support in the archaeological record for any importance attached to the orientation of the back walls of room blocks of unit pueblos or Great Houses. None of the putative alignments to the sun or moon has been visually or photographically confirmed. Application of Student's t-test 
to assess Sofaer's (2007) five claimed back-wall lunar standstill alignments, as well as her claimed June Solstice alignment at Aztec, indicates that five of the six are rejected at the 95\% confidence level. In addition, the claimed back-wall alignments are associated with a small subset of SSE-facing structures from the period. There are no architectural or cultural justifications for focusing on these perpendicular azimuths, other than the fact that this subset exhibits inaccurate association with celestial events. We suggest that the associations are coincidental; a classic selection effect (Malville \& Munro 2009).

The durability of the SSE orientation tradition, from at least AD 450 to 1140, is remarkable. Because the SSE orientation does not vary with latitude, we do not believe it is plausibly linked to direct observation of a celestial object. Similarly, no common terrestrial horizon features are observable across the wide area where the tradition is evident. For these reasons we have concluded that the orientation tradition was culturally important, and was most plausibly achieved using some form of consistent indirect measurement technique or tool associated with celestial observations.

We have identified a single ethnographic fragment that plausibly relates to these SSE orientations. The migration myth of the Snake Clan as reported by A.M. Stephen to Mindeleff (1891: 18) states in part:

"A brilliant star arose in the southeast, which would shine for a while and then disappear. The old men said, 'Beneath that star there must be people,' so they determined to travel toward it. They cut a staff and set it in the ground and watched till the star reached its top, then they started and traveled as long as the star shone; when it disappeared they halted. ... sometimes many years elapsed before it appeared again. When this occurred, our people built houses during their halt; they built both round and square houses. . They waited till the star came to the top of the staff again, then they moved on ..."

This tradition explicitly describes the use of a staff to enable stellar navigation to the southeast during migration. The use of some form of cross-staff to measure angles from a celestial object at its meridian height is consistent with the description. We suggest that construction surveys using the same type of staff could account for the SSE orientation evidence. Once such a tool was developed, interpretation of when or how a star 'arose' or 'disappeared' would become a secondary question; the tool itself could provide the means to achieve reasonably consistent travel directions, or building orientations. Any celestial object at its meridian height would provide a workable beacon. Notwithstanding, this single (and somewhat enigmatic) ethnographic fragment is far from conclusive. We are not aware of any such cross-staffs documented in association with Pueblo culture. We therefore suggest that additional ethnographic research and review of Chacoan material cultural evidence is appropriate to test this hypothesis.

\subsection{North-south and east-west 'cardinal' alignments}

Alignments with the cardinal directions are emblematic of Chaco, and especially of the 11th-century period of the 'Chaco Fluorescence'. With construction beginning AD 9901010, Hungo Pavi is less than $5^{\circ}$ offset from true NS. Pueblo Alto, built beginning AD 1020-1040, includes a more accurate EW wall. Sometime after AD 1070, Pueblo Bonito completed its staged reorientation from SSE to accurate NS/EW cardinal alignment (Fig. 1). As shown in Table 1, by the time large-scale construction ended at Chaco Canyon ( $\sim$ AD 1140) six of the 25 structures in our sample included more-or-less accurate NS and/or EW alignments. In addition, the well documented inter-site cardinal NS alignments across the center of 'downtown Chaco' involving Pueblo Alto, Tsin Kletsin, New Alto, and Casa Rinconada were completed at this time (Ashmore 2007; Fritz 1978; Sofaer 2007). 


\section{Pueblo Bonito AD 925 \\ Pueblo Bonito AD 1075+}

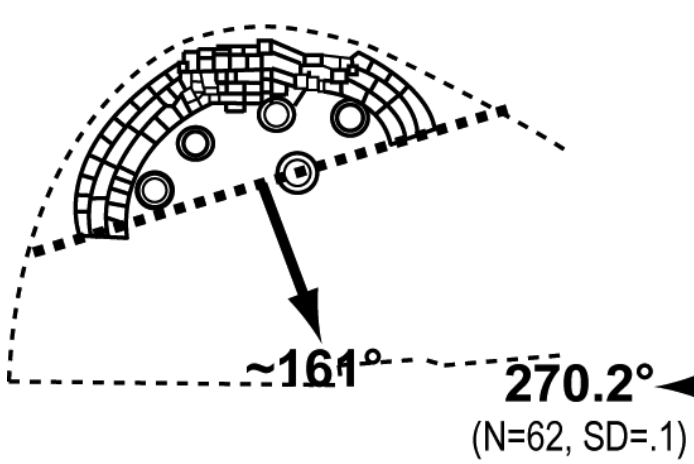

Adapted from Stein et al, 2003

\section{Adapted from Stein et al, 2003}

Figure 1. Pueblo Bonito's multiple stages of construction and expansion began with a clear SSE orientation, and concluded with accurate cardinal NS/EW alignments.

Among these intra-site and inter-site cardinal alignments, we have found that Pueblo Bonito is the most precisely and accurately aligned. Notwithstanding, theodolite survey and photography demonstrate that proposed visual equinox alignments at Pueblo Bonito (Farmer 2003; Sofaer 1997) do not function owing to the elevation of the horizons (Munro \& Malville 2009).

\subsection{Construction at solstice calendrical stations}

Early work on horizon calendars at Chaco included identification of a workable calendrical station at 29SJ 931, above Wijiji Great House. The pillar foresight at this location operates for December solstice sunrise, as well as offering the potential to enable anticipatory observations (Williamson 1984: 88-92; Zeilik 1989). Anticipatory foresights for approximately 2 weeks prior to a date of ritual significance have been discussed extensively in the literature as useful to enable advanced coordination and pilgrimage travel for upcoming festivals (see e.g., Zeilik 1985a, 1987; Malville \& Malville 2001a, 2001b).

The first horizon calendar confirmed that is observable from a Great House includes a workable June solstice sunrise marker, visible at Pueblo Bonito (Zeilik 1985c, 1989). During the 1990s, dramatic December solstice sunrise markers were found at Wijiji and Kin Kletso. These two calendrical horizons include anticipatory markers, and are photographically confirmed (Malville et al. 1996; Malville 2008: 70-71). We have subsequently confirmed that new construction at workable calendrical stations is a consistent feature among Great Houses built in Chaco after AD 1100. Solstice sunrise or sunset markers are observable from all of the 'new' low-lying in-canyon Great Houses from this period.

The eastern horizon from the now-backfilled site at Headquarters Site A (Fig. 2) is perhaps the most dramatic. December solstice sunrise emerges from a deep notch in the mesa wall. The sunrise is first observable from the westernmost extent of the building footprint, and visually exits the top of the notch as observed some ten minutes later from the easternmost extent of the structure. The inset photos show sunrise as seen from different locations within the Great House footprint. The identification of solstice 


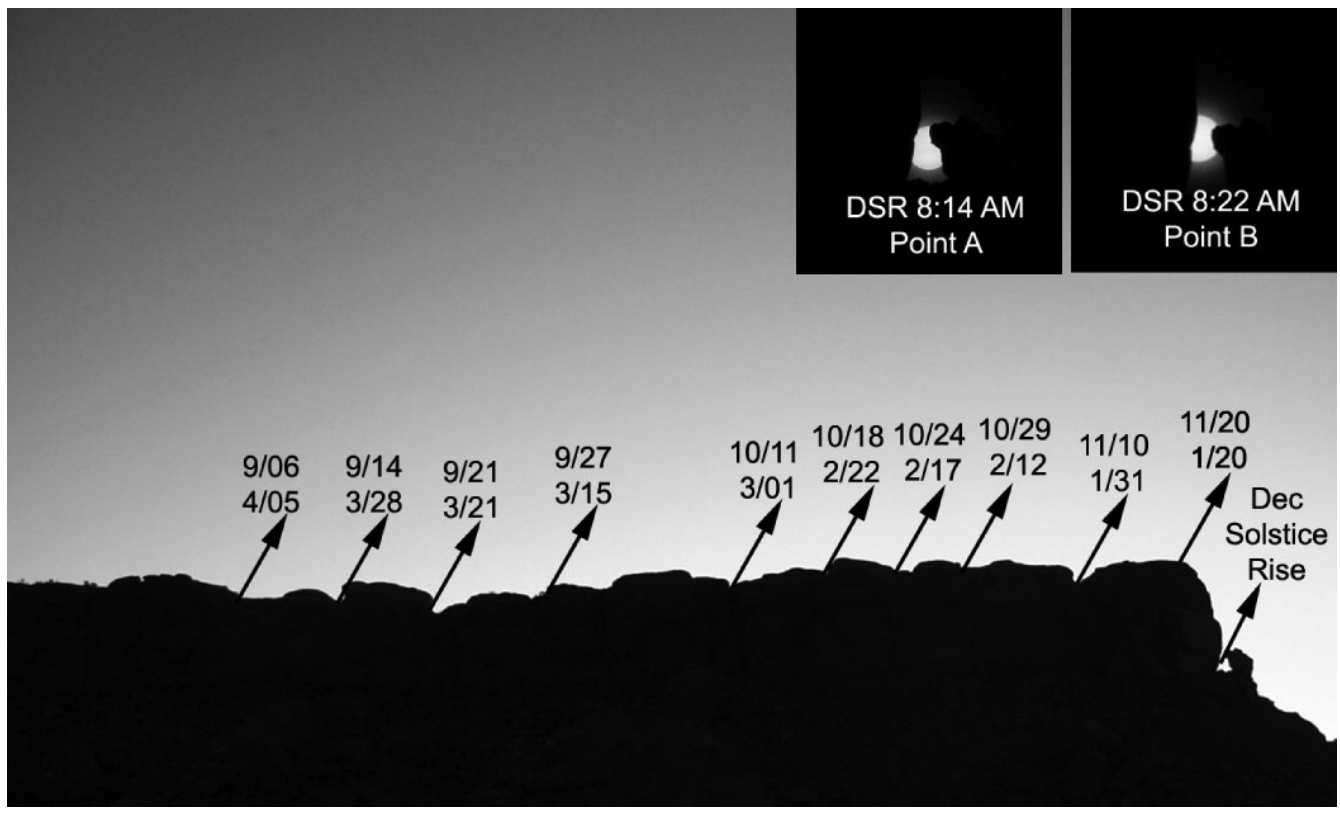

Figure 2. East horizon at Headquarters Site A with forecasted sunrise dates, and (insets) December Solstice Rise (DSR) confirmation photographs.

horizon markers at multiple Great Houses from the period after AD 1100 supports the idea that these structures were deliberately designed as public statements of astronomical knowledge and ritual power. We believe that these buildings most likely represent a centrally planned effort to reinvigorate a waning ritual/political system at Chaco, as suggested by Van Dyke (2008) (Munro \& Malville 2010a).

\section{Temporal assessment: Chaco and the Totah}

We initially assessed the cardinal and SSE traditions by comparing pit structures in early villages with later Bonito Phase Great Houses. Consistent with Hayes (1981) we found that during both periods there were a mix of cardinal (NS/EW) and SSE structures (Malville \& Munro 2009). For the later Great House construction period, Lekson (2009) interprets the cardinal (NS/EW) and SSE orientation as architectural hallmarks of at least two competing political factions, each with its own conceptual framework. He suggests use of these orientations to mark faction-dominance at the time of construction, and contrasts the dominant NS/EW cardinal tradition at Chaco during the late 11th and early 12th centuries with the dominance of the SSE tradition at Salmon and Aztec to the north in the Totah region.

While we differ in the interpretation of the SSE orientation tradition (which he terms 'solstitial') we concur with Lekson that temporal analysis of construction dates for associated orientation or placement traditions can provide insight into shifts in cultural dominance among ancestral Pueblo groups. Fig. 3 presents a temporal analysis of new construction starts for the three astronomically-linked architectural traditions among the twenty four Great Houses and one Great Kiva in this study. In this figure, each site is associated with traditions cumulatively; so the total sample size is exceeded by the sum of identified characteristics. 


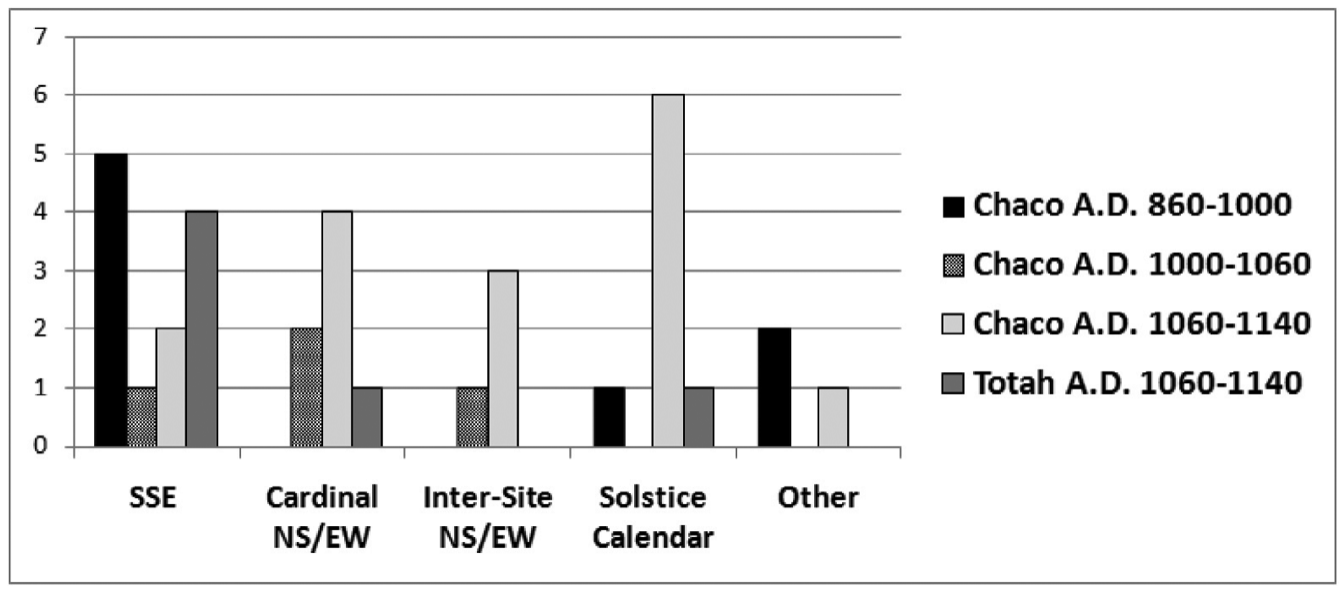

Figure 3. Great House and Great Kiva construction starts by region and period.

A majority of the Great Houses built before AD 1000 at and near to Chaco are oriented to the SSE. Only one (Pueblo Bonito) has a workable calendrical horizon for a solstice date, and its horizon is not visually dramatic. During the first half of the 11th Century, SSE dominance is maintained, but the NS/EW cardinality that was evident in earlier pit structures begins to reemerge. Sometime after AD 1070, Pueblo Bonito completed its gradual reorientation from SSE to accurate cardinality. After AD 1100 a major shift occurs at Chaco; while existing SSE structures in the canyon were expanded (e.g., Chetro Ketl), all subsequent new Great House construction establishes either cardinal NS/EW alignments (site-level and/or inter-site), or is located at workable calendrical stations with solstice sunrises or sunsets. In contrast, among the five new Great Houses built in the Totah region, four are clearly associated with the SSE orientation tradition. The 'halo' Great House at Bis sa'ani, some 10km northeast of Wijiji on Escavada Wash, is the sole example found to date that incorporates all three traditions. It includes a NS/EW cardinal alignment, a SSE room block, and a working calendrical horizon that marks solstices (Munro \& Malville 2010b).

\section{Interpretation and conclusions}

We interpret the SSE tradition as commemorative of migration mythology, an implicit form of ancestor veneration. While additional research is needed to fully justify this idea, we suggest that it is more consistent with the body of evidence than previous hypotheses. It is well-documented ethnographically that the cardinal NS/EW tradition is explicitly linked to Eastern Pueblo cosmology. Because the 'solstice' calendrical station Great Houses were most plausibly built at sites where ancestral 'sacred' sun watching had occurred, they may combine visual astronomical references and commemoration or veneration of ancestral ritual activity.

These three traditions appear to provide indicators of at least two distinct Pueblo cultural affiliations, and offer the potential to trace migration paths in time and space. The notable change in dominance from SSE orientation to a combination of cardinal NS/EW alignments and solstice calendrical station locations during the late 11th and early 12th centuries does suggest the likelihood of social schism or fragmentation (Lekson 2009: 127; 238; 308n56). The SSE tradition emerges as dominant in the Totah at that time; indicative of northward migration by a 'SSE faction'. Notwithstanding, multiple 
pieces of evidence suggest that changes in dominance among the groups did not equate to absolute social schism. The Bis sa'ani Great House just north of Chaco Canyon uniquely combines all three traditions. In the Totah, the NS orientation of Aztec North Great House is associated with a group of SSE dominant structures, and Chimney Rock combines SSE and solstice-calendrical associations (Malville 2004). The traditions continued to coexist in each region in spite of apparent changes in social dominance over time.

We note with particular interest the remarkable consistency of the three traditions; all of the studied Great Houses or Great Kivas built between the 10th and early 12th centuries within Chaco Canyon and the Totah save three manifest one or more of these traditions. The exceptions are Kin Nahasbas (late AD 800s, facing $\sim 205^{\circ}$ ), Peñasco Blanco (AD 900, facing $\sim 113^{\circ}-116^{\circ}$ ), and Pueblo del Arroyo (AD 1065, facing $114.9^{\circ}$ ). We note with interest that two of these face east-southeast, and that all three exceptions share a common trait. They are all rotated by $\sim 25^{\circ}$ with respect to one of the cardinal directions. Kin Nahasbas faces $25^{\circ}$ west of due south; Peñasco Blanco and Pueblo del Arroyo both face $\sim 25^{\circ}$ south of due east. The $25^{\circ}$ offset is remarkably similar to the mean offset from cardinal south for a majority of the SSE structures. The mean of SSE orientations between $151^{\circ}$ and $161^{\circ}$ is $\sim 154^{\circ}$, or $24^{\circ}$ east of due south. We speculate that a common survey tool such as the cross-staff discussed above may have been applied in different ways to achieve all three orientations ( $\mathrm{SSE}, \sim 115^{\circ}$, and $205^{\circ}$ ).

Astronomical associations with architecture have emerged as a clear cultural marker among ancestral Pueblo people. Construction survey for both the SSE and NS/EW traditions may have been conducted with technology such as gnomons and cross-staffs. It is notable that all three of the identified astronomically associated traditions are plausibly visual in origin. Of greatest interest, the association of Chacoan monumental architecture with visual astronomy in the late 11 th and early 12 th centuries may have been intended to increase Chaco's attractiveness as a pilgrimage destination. Public ceremonies involving predicted solstice sunrises and sunsets would make for powerful social bonding experiences. Similarly, the NS inter-building alignments provided opportunities for nighttime events where spectators could observe that a Great House was aligned directly under the visible void in the north about which the night sky rotates. These sites would have offered public demonstrations of the astronomical knowledge, predictive power, and legitimacy of the Chacoan elite.

\section{Acknowledgements}

This work was made possible by fieldwork support from Robert and Beverly Beehler, Nancy Malville, Gene McCracken, Anne Marie Munro, Donald D. Munro IV, John Nickerson, and Greggory Rothmeier. National Park Service and Bureau of Land Management staff that assisted in permitting, planning and research include Russ Bodnar, Tracy Bodnar, Wendy Bustard, Jim Copeland, G.B. Cornucopia, Dabney Ford, Peggy Gaudy, Roger Moore and Barbara West.

\section{References}

Ashmore, W. 2007, in S. H. Lekson (ed.), The Architecture of Chaco Canyon, New Mexico, University of Utah Press, Salt Lake City, p. 179.

Baker, L. 2008, in P. F. Reed (ed.), Chaco's Northern Prodigies: Salmon, Aztec, and the Ascendancy of the Middle San Juan Region after AD 1100, University of Utah Press, Salt Lake City, p. 29.

Brown, G. M., Windes, T. C., \& McKenna, P. 2008, in P. F. Reed (ed.), Chaco's Northern Prodigies: Salmon, Aztec, and the Ascendancy of the Middle San Juan Region after AD 1100, University of Utah Press, Salt Lake City, p. 231. 
Cameron, C. M. 2009, Chaco and After in the Northern San Juan: Excavations at the Bluff Great House, University of Arizona Press, Tucson.

Eddy, F. W. 1977, Archaeological Investigations at Chimney Rock Mesa: 1970-1972, Memoir No. 1, Colorado Archaeological Society, Boulder.

Farmer, J. D. 2003, in J. E. Neitzel (ed.), Pueblo Bonito: Center of the Chacoan World, Smithsonian Books, Washington DC, p. 61.

Fritz, J. M. 1978, in C. L. Redman (ed.), Social Archaeology: Beyond Subsistence and Dating, Academic Press, New York, p. 37.

Hayes, A. C. 1981, in A. C. Hayes, D. M. Brugge \& W. J. Judge (eds), Archaeological Surveys of Chaco Canyon, New Mexico, University of New Mexico Press, Albuquerque, p. 1.

Kantner J. W. \& Kintigh, K. W. 2006, in S. H. Lekson (ed.), The Archaeology of Chaco Canyon: an Eleventh-Century Pueblo Regional Center, School of American Research Press, Santa Fe, p. 153.

Kantner J. W. \& Mahoney, N. M. (eds) 2000, Great House Communities across the Chacoan Landscape, University of Arizona Press, Tucson.

Kincaid, C. (ed.) 1983, Chaco Roads Project Phase I, a Reappraisal of Prehistoric Roads in the San Juan Basin, Bureau of Land Management, Albuquerque.

Lekson, S. H. 1984, Great Pueblo Architecture of Chaco Canyon, New Mexico, University of New Mexico Press, Albuquerque.

Lekson, S. H. (ed.) 2006, The Archaeology of Chaco Canyon: an Eleventh-Century Pueblo Regional Center, School of American Research Press, Santa Fe.

Lekson, S. H. 2009, A History of the Ancient Southwest, School for Advanced Research Press, Santa Fe.

Lekson, S. H., Windes, T. C., \& McKenna, P. J. 2006, in S. H. Lekson (ed.), The Archaeology of Chaco Canyon: an Eleventh-Century Pueblo Regional Center, School of American Research Press, Santa Fe, p. 67.

Lipe, W. D. 2006, in S. H. Lekson (ed.), The Archaeology of Chaco Canyon: an Eleventh-Century Pueblo Regional Center, School of American Research Press, Santa Fe, p. 261.

Lister, R. H. \& Lister F. C. 1981, Chaco Canyon, University of New Mexico Press, Albuquerque.

McCluskey, S. C. 1977, Journal for the History of Astronomy 8, 174.

Malville, J. M. 2004, in J. M. Malville (ed.), Chimney Rock: the Ultimate Outlier, Lexington Press, Boulder, p. 131.

Malville, J. M. 2008, Guide to Prehistoric Astronomy in the Southwest, Johnson Books, Boulder.

Malville, J. M., Cornucopia, G. B., \& Watson, R. 1996, The Three Faces of Piedra del Sol (29SJ514), Chaco Canyon. Paper presented at the Fifth Oxford International Conference, Santa Fe, New Mexico.

Malville, J. M. \& Malville, N. J. 2001a, in D. P. Dubey (ed.), Pilgrimage Studies: the Power of Sacred Places, The Society of Pilgrimage Studies, Allahabad, p. 206.

Malville, J. M. \& Malville, N. J. 2001b, Kiva 66, 327.

Malville, J. M. \& Munro, A. M. 2009, Cultural Identity, Continuity, and Astronomy in Chaco Canyon. Paper presented at the 2009 Conference on Archaeoastronomy of the American Southwest, Camp Verde, Arizona.

Mathien, F. J. \& Windes T. C. 1988, Historic Structure Report, Kin Nahasbas Ruin, Chaco Culture National Historic Park, New Mexico, National Park Service Branch of Cultural Research, Santa Fe.

Mindeleff, V. 1891, A Study of Pueblo Architecture in Tusayan and Cibola, Government Printing Office), Washington DC.

Munro, A. M. \& Malville, J. M. 2009, Calendrical Stations in Chaco Canyon. Paper presented at the 2009 Conference on Archaeoastronomy of the American Southwest in Camp Verde, Arizona.

Munro, A. M. \& Malville, J. M. 2010a, Astronomy and the Design of Late Bonito Great Houses at Chaco Canyon. Paper presented at the 2010 Society for American Archeology Annual Meeting symposium on Archaeoastronomy in the Americas, Saint Louis, Missouri.

Munro, A. M. \& Malville, J. M. 2010b, Journal of Cosmology 9, 2147 (http://journalof cosmology.com/AncientAstronomy115.html).

Noble, D. G. (ed.) 2004, In Search of Chaco: New Approaches to an Archaeological Enigma, School of American Research Press, Santa Fe. 
Ortiz, A. 1969, The Tewa World: Space, Time, Being and Becoming in a Pueblo Society, The University of Chicago Press, Chicago.

Powers, R. P., Gillespie, W. B., \& Lekson, S. H. 1983, The Outlier Survey: a Regional View of Settlement in the San Juan Basin, Reports of the Chaco Center No. 3, National Park Service, Albuquerque.

Reed, E. K. 1956, in G. R. Willey (ed.), Prehistoric Settlement Patterns in the New World, Wenner-Gren foundation for Anthropological Research, New York, p. 11.

Sebastian, L. \& Atschul, J. H. 1986, Site Typology, and the Demographic Analysis: the Anasazi, Archaic, and Unknown Sites, Contract PX 7029-5-C041, Chaco Culture NHP Museum Archive at the University of New Mexico, Albuquerque.

Snead, J. E. \& Preucel, R. W. 1999, in W. Ashmore \& A. B. Knapp (eds), Archaeologies of Landscape, Blackwell, Oxford, p. 169.

Sofaer, A. (1997), The primary architecture of the Chacoan Culture: a cosmological expression. In B. H. Morrow \& V. B. Price (eds), Anasazi Architecture and American Design, University of New Mexico Press, Albuquerque, p. 88.

Sofaer, A. 2007, in S. H. Lekson (ed.), The Architecture of Chaco Canyon, New Mexico, University of Utah Press, Salt Lake City, p. 225.

Stein, J. R., Ford, D., \& Friedman, R. 2003, in J. E. Neitzel (ed.), Pueblo Bonito: Center of the Chacoan World, Smithsonian Books, Washington DC, p. 33.

Stirling, M. W. 1942, Origin Myth of Acoma and Other Records, Bulletin 135, Bureau of American Ethnology, Washington DC.

Van Dyke, R. M. 2008, The Chaco Experience: Landscape and Ideology at the Center Place, School for Advanced Research Press, Santa Fe.

Vivian, G. \& Reiter, P. 1960, The Great Kivas of Chaco Canyon and their Relationships, School of American Research, Santa Fe.

Wilcox, D. R. 2004, in J. M. Malville (ed.), Chimney Rock: the Ultimate Outlier, Lexington Books, Lanham, p. 163.

Williamson, R. A. 1984, Living the Sky: the Cosmos of the American Indian, University of Oklahoma Press, Norman.

Wilshusen, R. H. \& Van Dyke, R. 2006, in S. H. Lekson (ed.), The Archaeology of Chaco Canyon: an Eleventh-Century Pueblo Regional Center, School of American Research Press, Santa Fe, p. 211.

Windes, T. C. 1984, in S. H. Lekson (ed.), Great Pueblo Architecture of Chaco Canyon, New Mexico, University of New Mexico Press, Albuquerque, p. 192.

Windes, T. C., Anderson, R. M., Johnson, B. K., \& Ford, C. A. 2000, in: J. Kantner \& N. M. Mahoney (eds), Great House Communities across the Chacoan Landscape, University of Arizona Press, Tucson, p. 39.

Windes, T. C. \& Ford, D. 1992, in D. E. Doyel (ed.), Anasazi Regional Organization and the Chaco System, Anthropological Papers Number 5, Maxwell Museum of Anthropology, University of New Mexico, Albuquerque, p. 75.

Zeilik, M. 1985a, Archaeoastronomy (suppl. to Journal for the History of Astronomy, 8, S1.

Zeilik, M. 1985b, Archaeoastronomy (suppl. to Journal for the History of Astronomy, 9, S86.

Zeilik, M. 1985c, Archaeoastronomy (suppl. to Journal for the History of Astronomy, 9, S69.

Zeilik, M. 1986, Archaeoastronomy (suppl. to Journal for the History of Astronomy, 10, S1.

Zeilik, M. 1987, in J. B. Carlson \& W. J. Judge (eds), Astronomy and Ceremony in the Prehistoric Southwest, Maxwell Museum, Albuquerque, p. 25.

Zeilik, M. 1989, in A. F. Aveni (ed.), World Archaeoastronomy, Cambridge University Press, Cambridge, p. 143. 